\title{
LA ENSAYÍSTICA DE MARTÍN CERDA
}

\author{
José Alberto de la Fuente $\left(^{*}\right)$
}

\begin{abstract}
RESUMEN
El propósito de este trabajo es realizar un rastreo y precisión de las categorías ensayísticas de Martín Cerda (1930-1991). Se sabe que escribió más de cuatro mil fragmentos y algunos libros completos que se quemaron en su residencia de la Universidad de Punta Arenas. Actualmente, sólo contamos con la evidencia de tres recopilaciones y un libro -La palabra quebrada, ensayo sobre el ensayo, (1982)- el cual tiene un tema situado y una orgánica que permite apreciar las características de su estilo, la finalidad que le atribuye al ensayo, justificar sus localizaciones y meditaciones sobre Montaigne, la visión burguesa del mundo y otras cuestiones como el exilio, las guerras y las enfermedades.

En contribución a los estudios eidéticos, la obra de Martín Cerda no puede seguir postergándose en el campo de la teoría y de la crítica literaria. En esta oportunidad, según mi perspectiva y pauta de lectura, comparto los resultados de un ejercicio hermenéutico sobre el Vivir, el Leer, el Escribir, el Ensayar, el Ensayo, el Ensayista y el Crítico. Mi hipótesis es la siguiente: El discurso crítico de Martín Cerda identifica a un tipo de intelectual que más que preocuparse de cómo vivir, sus esfuerzos académicos y cotidianos están puestos en cómo pensar el mundo a partir de sus experiencias políticas, estéticas, discursivas y culturales, escritas al margen de los textos y del reconocimiento social.

Los fragmentos y retazos que conocemos de su obra, son el resultado de disquisiciones y preguntas que emergen al mundo real a través del "alma y las formas" de la literatura moderna y contemporánea, concibiendo al lector como la posibilidad de mitigar un destino desde la sensibilidad poética, de la observación científica y de las conversaciones.
\end{abstract}

$\left.{ }^{*}\right)$ Doctor en Estudios Americanos, (Universidad de Santiago de Chile). Académico de las Universidades Ucsh - Usach.

Artículo recibido el 12 de agosto de 2010. Aceptado por el Comité Editorial el 29 de septiembre de 2010.

Correo electrónico: josepepe.delafuente@gmail.com 
Palabras clave:

Vivir - leer - escribir - ensayar - ensayo - ensayista- crítico.

\begin{abstract}
The purpose of this work is to search and essayistic defined categories of Martin Cerda (1930-1991). We know who wrote more than four thousand fragments and some complete books were burned at his residence at the University of Punta Arenas, now we have only the evidence of three collections and a book La palabra quebrada, ensayo sobre el ensayo (1982), which has a theme and an organic set can appreciate the characteristics of his style, the purpose assigned to the essay, justifying their locations and meditations on Montaigne, bourgeois view of the world and other issues such as exile, wars and diseases.

In contribution to the studies eidetic, Martin's work can no longer be delayed sow in the field of theory and literary criticism. In this opportunity, in my perspective and reading frame, share the results of a hermeneutic exercise on live, reading, write essay, essays, essayist and critical. My hypothesis is as follows: The critical discourse of Martin Cerda identifies a type of intellectual rather than worry about how they live their everyday academic efforts are on how to think about the world from his political experiences, aesthetic and cultural discourse apart from written texts and social recognition.

The bits and pieces that we know of his work, are the result of digressions and questions that emerge in the real world through the "soul and the forms" of modern literature and Contemporary she sees the reader as the possibility of mitigating a destination from the poetic sensibility of scientific observation and conversations.
\end{abstract}

Key words:

Live - reading - writing - write essay - essays - essayist - critical.

\title{
INTRODUCCIÓN
}

Cualquier aproximación que se haga a la ensayística de Martín Cerda (1939-1991), por ahora es provisoria e incompleta. Se sabe que escribió más de cuatro mil fragmentos. Entre su "papelería dispersa" se pueden clasificar crónicas, glosas, bocetos, pedazos, diálogos rotos, monólogos quebrados, conversaciones inconclusas, comentarios, parergas, etc., y el estudioso sólo cuenta con la evidencia de tres recopilaciones y el libro La palabra quebrada, ensayo sobre el ensayo (1982), que tiene un tema situado y una orgánica que permite apreciar las características de su estilo, la finalidad que le atribuye al ensayo, justificar sus localizaciones y meditaciones sobre Montaigne y de ahí vincularse a otros intelectuales y escritores como Rabelais, Cervantes, Shakespeare, Racine, Goethe, Lukács, Drieu La Rochelle, Barthes, Valéry, Marx, Louis-Ferdinand Céline, Jaspers, Gorki, Nietzsche, Ortega y Gasset, de Unamuno, Kafka, Flaubert, Freud, Spengler, Benjamin, Jünger, Voltaire, Gramsci, Sorel, Leiris, Adorno, Blanchot, Cioran, 
Axelos, Caillois, Bataille, Levi Strauss, Goldmann, Weber, Todorov. Entre los chilenos y latinoamericanos, hace referencias a Paz, Cid, Teillier, Donoso, Droguett, Edwards Bello, Benjamín Subercaseaux, Flora Yáñez, Oyarzún, Teresa Wilmms, Huidobro, Mistral, Neruda, de Rokha, Prado. La mayoría de sus escritos tienen como telón de fondo las contradicciones y conflictos derivados de la visión burguesa del mundo y recorren la historia del exilio, de las guerras y de las enfermedades de la humanidad ${ }^{1}$.

El primer libro que Martín Cerda autorizó publicar en Chile fue La palabra quebrada, ensayo sobre el ensayo (1982) que podría calificarse como "sociología de la escritura fragmentada", recomposición de capítulos "desgranados" que responden al proceso de descomposición de la sociedad contemporánea; su estilo cristaliza en las narrativas de la decadencia de clases y grupos en el capitalismo y en el stalinismo. Luego, la Biblioteca Nacional de Chile, recopila Ideas sobre el ensayo (1993) y Palabras sobre palabras (1997). El poeta Alfonso Calderón, gestiona la recopilación Escombros, apuntes sobre literatura y otros asuntos (2008), escribiendo el prólogo "desde las fisuras de este mundo" y se plantea la pregunta qué significa tener la vida por delante en una sociedad que rechaza el oficio de escritor; señala que los escombros no son siempre ruinas, también pueden ser un pasado memorable si se convierten en la sombra de lo que fuimos. En efecto, esta exposición provisoria e incompleta corresponde al 12 por ciento de su ensayística, contenida en menos de novecientos páginas, más algunos artículos dispersos difundidos en periódicos aún no recopilados.

También se sabe que nunca publicó la traducción al español de El elogio de la filosofía de Marleu Ponty y que al incendiarse su librería ambulante en la casa de huéspedes de la Universidad de Punta Arenas, el 13 de agosto de 1990 (el 29 del mismo mes ya estaba internado con un infarto al miocardio), pierde los libros Montaigne y el nuevo mundo, Historia del género del ensayo y Los viajeros del Austro, en el cual estudia las peripecias de los viajeros de la zona austral.

En contribución a los estudios eidéticos, la obra de Martín Cerda, a pesar de los "vestigios" que quedan de ella, no puede seguir postergándose en el campo de la teoría y de la crítica literaria. En este trabajo, según mi perspectiva y pauta de lectura, comparto los resultados de un ejercicio hermenéutico según la secuencia: El Vivir, continúa en el Leer, sigue su marcha en el Escribir, avanza en el Ensayar, se concreta en el Ensayo y su caracterización, zarpa y naufraga en el Ensayista y se justifica en el Crítico, cuyo oficio parte desde un primer lenguaje, la obra que precede a su acción o que sirve de pretexto. Mi hipótesis es la siguiente: El discurso crítico de Martín Cerda identifica a un tipo de intelectual que más que preocuparse de cómo vivir, sus esfuerzos académicos y cotidianos por la subsistencia personal y sentido del ensayo, están puestos en cómo pensar el mundo a partir de sus experiencias políticas, estéticas, discursivas y culturales, escritas al margen de los impresos y del reconocimiento social.

\footnotetext{
${ }^{1}$ En el fragmento recopilado en Escombros intitulado "1980: una sugerencia", Cerda dice que "lo que podemos llamar (en Occidente por lo menos) la cultura del siglo XX, es, en lo más esencial, el producto de una generación de pensadores y científicos nacidos en torno a 1885. Bastan sólo algunos nombres para precisarlo e ilustrarlo: Apollinaire y Spengler, Ortega y Pound, Einstein y Picasso, Chaplin y Musil, Joyce y Lukács, Mahler y Heidegger, Wittgenstein y Kafka", p. 84.
} 
Los fragmentos y retazos que conocemos de su obra, son el resultado de disquisiciones y preguntas que emergen al mundo real a través del "alma y las formas" de la literatura moderna y contemporánea, concibiendo al lector como la posibilidad de mitigar un destino desde la sensibilidad poética, de la observación científica y de las conversaciones.

\section{El Vivir}

¿Cómo se hace o nace un ensayista? En la pluma de Martín Cerda, pareciera que es inseparable e indivisible la vida personal de la vida intelectual. Simultaneidad entre el ser y el pensar, entre el intuir y el razonar.

Nace el 11 de septiembre de 1930 y fallece el 12 de agosto de 1991. A los veinte años viaja a París y allí lo recibe la ciudad-escenario de la ruinosa experiencia de la Segunda Guerra Mundial. Estudia filosofía. Se identifica con una generación que desea cambiar el mundo y que un día descubre "el fracaso de la ilusión revolucionaria en todos los registros de la existencia". Siempre tuvo la obsesión de vivir en una sociedad enmascarada, sensación que reconocía en las obras de los escritores de su generación, los chilenos José Donoso, Jorge Edwards y del poeta Enrique Lihn. Una de las contribuciones clave para entender el vínculo indisoluble de la vida del ensayista, con la forma y el contenido, el material y la materia de sus escritos, es una referencia a la dimensión que tiene Mijaíl Bajtín con los formalistas rusos, justificando a su vez la importancia de Geög Lukács por su libro El alma y las formas o la teoría de la novela (1911). En el libro La palabra quebrada, ensayo sobre el ensayo (1982), se pregunta para qué vive el ensayista y dice: "para discutir ideas, comentar libros e interpretar obras, estilos, formas. Esta perpetua polémica con la cultura instituida, "sacralizada" o doxologizada arrastra, sin embargo, un pleito más radical con la sociedad que la "sacraliza" o doxologiza. Por eso, justamente, toda "crítica cultural" involucra, de un modo u otro, a la sociedad, y esta, a su vez, estigmatiza, sanciona o margina al ensayista, como decía Theodor Adorno por puro miedo a la negatividad" ${ }^{2}$. A base de esta argumentación, nuevamente vuelve a Lukács para afirmar que "la vida no es nada, la obra es todo". Si la vida no es una forma, no alcanza a devenir en obra. Igual que Montaigne, defiende en sus ensayos la mesura, la tolerancia y la confianza en el discurso de la razón. En conclusión, para Martín Cerda, tras las huellas de su maestro, acepta que vivir es asumirse en libertad de conciencia.

\section{El Leer}

Martín Cerda se construye en sus palabras ensayísticas a través de la lectura incesante y sostenida, entre la programación, la dispersión y la circunstancia. Lee, se informa, anota, glosa, articula pensamientos en el lenguaje de la prosa que busca fijar sus experiencias en nociones, conceptos y categorías. De este modo deviene en la comprensión e interpretación de una realidad que es también la propia. Para nuestro autor, la vida moderna está mediatizada por el acto de la lectura. Leer es "co-producir, es hacer hablar lo que los textos callan, retienen o sugieren irónicamente. Un escrito no es nunca una cosa, sino más bien, como observa Richard E. Palmer, es siempre

${ }^{2}$ Cerda, Martín (1982), La palabra quebrada, ensayo sobre el ensayo, p. 28. 
un suceso, algo que transcurre cada vez que un hombre lee lo que otro escribió. La historia de los grandes libros es, en efecto, la historia de sus lecturas mayores, canónicas o ejemplares" ${ }^{3}$. Saber leer es saber mirar. Lo que distingue al hombre culto del bárbaro es saber mirar. Es lo que hace Walter Benjamin a partir de la miniatura, de la migaja, de la mirada micrológica. Coincide con Annah Arendt, quien decía que "el tamaño de un objeto estaba en razón inversa de su significado (...) Lo que distingue al hombre culto del bárbaro no es, después de todo, una ciencia ni una técnica, sino, más bien, un arte: el arte de mirar. Esta es la lección ejemplar que, en nuestros días puede enseñarle el más humilde indio makiritare, celoso guardián de la sabiduría elemental de las selvas guayanesas, al tecnócrata barbarizado que sólo ve en ellas pulgadas de madera". Saber mirar lo mínimo, como supo Benjamin, es un imperativo, porque -conforme lo indicaba Ortega- para quien lo pequeño no es nada, no es grande lo grande" ${ }^{\prime \prime}$.

\section{El Escribir}

Para Martín Cerda escribir es predecir; es mantener la fe en las utopías, pero con un grado de desencanto y aceptar el mundo como drama y peripecia. "Escribir es, en efecto, mentirse siempre un poco a sí mismo, prometiéndose que mañana reencontraremos, en algún rincón imaginario de la Tierra, aquello que perdimos hace una eternidad. Quizá por eso olvidamos a los escritores que sólo hablan de sí mismo, impidiendo de ese modo que su diario comercio con el mundo se transparente en lo que escriben (...) Un hombre modesto -decía La Bruyère- no habla casi de sí mismo. Las heridas que nos hace ir dejando un poco en todas partes algo de nuestras ilusiones, son usualmente tan banales que no merecen montar un espectáculo con ellas. Aún las obras más desencantadas como Il mestiere di vivere de César Pavese, siempre ofrecen una mirada sobre el mundo"5.

En la escritura oracular, el futuro está propuesto como destino; sus temas son los de la decadencia, el mundo se prevé reducido a escombros. Un ejemplo es Oswald Spengler a través de sus ideas expuestas en La decadencia de Occidente (1918): "una cosa es, sin embargo, la escritura oracular de un Spengler o de un De Maistre, y otra su remedo. El pesimismo trágico de los escritores oraculares les impide, en efecto, sumarse a las utopías conservadoras que, cada cierto tiempo, repuntan en algún lugar de la tierra. El pensador trágico no conoce la paz, de la nostalgia ni la ilusión utópica de la esperanza, su escritura es sólo una pregunta al futuro, en un mundo en donde ningún signo, en el Cielo o en la Tierra, le garantiza una respuesta clara, firme e incuestionable"

Para Cerda hay dos modos del fracaso en la integración inseparable del Vivir-Escribir: 1) El mundano, cuando el escritor es incomprendido y desestimado por sus contemporáneos;

2) El histórico, cuando sus escritos no pueden responder a las preguntas más radicales de su tiempo y de su vida. En consecuencia, escribir bien y oportunamente es, como lo decía Flaubert "sentir bien, pensar bien y decir bien a la vez". Esto implica, en primer

\footnotetext{
${ }^{3}$ Cerda, Martín (1997), Palabras sobre palabras, p. 65.

${ }^{4}$ Cerda, Martín (2008), Escombros, apuntes sobre literatura y otros asuntos, p. 261.

${ }^{5}$ Cerda, Martín (1997), Palabras sobre palabras, p. 13.

${ }^{6}$ Op., cit., p. 48
} 
lugar, valorar o considerar la emoción como base de la reflexión y la experiencia convertida en pensamiento. En segundo lugar, la dialéctica del fluir intelectual proyectada a la búsqueda del sentido de las preguntas grandes y cruciales y en tercer lugar, el decir en forma, la acción verbal que permite organizar la emoción y la razón

en la armonía que agrada a la memoria, a la audición y a la lectura silenciosa ¿Entonces para qué se escribe? "Para encararse con la muerte. No se escribe, como algunos imaginan, para "eternizarse", sino más bien para aguantarse en la vida. Aguantarse es una expresión que le agradaba a Jean Beaufret (...) Cuando se afloja ese aguante, la angustia y la desesperación hacen lo suyo, y el hombre suele suicidarse"7.

En el libro La palabra quebrada, ensayo sobre el ensayo (1982), Cerda plantea que no hay escritura inocente. El escritor está siempre a la intemperie, expuesto en cada línea que escribe, en cada palabra que omite u olvida. Fundamentalmente, de acuerdo a su experiencia, hay dos tipos de escritura, la testimonial y la heurística. "Todo escrito testimonial es, en verdad, una respuesta, acto o gesto solitario destinado a preservar, de un modo u otro, la "individualidad" o, como lo hubiese escrito Kafka, la singularidad de un hombre en un mundo que la recusa, tacha o invalida. Todo escrito testimonial está, pues, anclado en una situación de incertidumbre, de indefensión o de peligro. Este "anclaje" privilegia, en sus expresiones más extremas, el valor cognitivo y moral de esos escritos que no tienen otro título de legitimidad que el de ser un ensayo de orientación en una situación de apremio extremo (...) La escritura heurística es todo discurso (biográfico, conceptual o ficticio) que está dispuesto, explícita o implícitamente, como una búsqueda, exploración o interrogación sostenida y que, en consecuencia, no puede avanzar si no es corrigiéndose, censurándose, comentándose $\mathrm{y}$, en algunos casos extremos, suprimiéndose $\mathrm{e}^{\prime \prime}$. Es la conciencia del naufragio, especialmente cuando deviene el diario autobiográfico.

La Revista Taller de Letras (U.C. 1972) le pregunta a Martín Cerda sobre los niveles que cabrían en la discusión de la literatura comprometida. A propósito de la obra de J. P. Sartre, Qué es la Literatura (1948), señala que el problema de la literatura llamada comprometida debe ser discutida en cuatro niveles diferentes, pero inseparables: negación del presente del mundo capitalista; reconocimiento del proyecto revolucionario o de la esperanza que le sirve de fundamento; concepción épico o trágica de la historia e hipótesis antropológica del hombre reconciliado. A partir de estas divisas afirmará que el escritor no es un médium ni un iluminado; es simplemente un ser prediscente, cuya función es hacer aparecer lo posible, anticipar o procursar la realidad como lo fueron los novelistas de las antiutopías más conocidas del siglo XX: Wells, Huxley, Orwell, Kafka. La gran misión del escritor es enseñar a convivir en la diversidad.

\section{El Ensayar}

El ensayar es el tiempo del gerundio; es la ocasión de escribir para intentar discurrir

7 Op., cit., p. 95.

8 Cerda, Martín, (1982). La palabra quebrada, ensayo sobre el ensayo, pp. 95 y 123. 
a partir de las preguntas y de anotaciones al margen de lecturas y de pensamientos que transforman la conciencia en escritura. Es la parerga, o si se quiere, el resultado de la lectura oracular, la soledad y la esperanza. Por eso que ensayar es "aguantarse en el mundo", una forma de resistencia, una concreción del imperativo ético y de las opciones valóricas.

El ensayar es la acción intelectual que cristaliza en palabras, en formas, en posibilidades de vivir. El ensayar siempre está vinculado al intento, al propósito del ensayo actual, a la intención de "introducir una mirada discontinua en un mundo que, en lo más sustantivo, se oculta o se enmascara con diferentes ropajes y lenguajes "totales", monolíticos y opresivos. Por eso, justamente, en su penetrante libro autobiográfico, Roland Barthes podía anotar: "Escribir en fragmentos: los fragmentos son entonces las piedras sobre el borde del círculo: me explayo en redondo: todo mi pequeño universo está hecho de migajas: en el centro ¿qué?". Por eso, asimismo, escribir sobre el ensayo exige siempre escribir ensayísticamente, es decir, de manera fragmentada, discontinua y exploratoria" ${ }^{\prime \prime}$. El ensayista es o debiera ser un intelectual que no sólo retorna una y otra vez a la tradición, sino que además eleva la discusión y no elude los problemas de su tiempo y menos los del porvenir. En los círculos pseudo universitarios, los textos más abundantes suelen ser aquellos que simulan y encubren la ausencia de un efectivo pensar, echando mano a un lenguaje de parodia; son las composiciones de los "neolálicos", los descontextualizadores de las referencias que revelan la flojera o ausencia del pensar lo propio en formas aparentemente significativas. Los plagiarios de la academia camuflan sus no-pensamientos como si lo único que existe fuese el oído de los chapuceros. Frente al futuro, hoy en día, el hombre es miedo y esperanza en medio de la amenaza del colapso planetario. Los "neolálicos" no son capaces de reinventarse utópicamente ante cada fracaso... La inanidad de su semántica suele poner en un mismo nivel las etiquetas y clichés verbales con los pensamientos disidentes, críticos, innovadores y profundos.

\section{El Ensayo}

El ensayo es ese género que siempre está en un proceso discontinuo de escritura; es el antes y el después en el instante del pensar-escribir; es el juego de posibilidades atisbando simultáneamente la tradición y el futuro. Exagium es el acto de pensar algo, acto verbal e intelectual que examina, que "so-pesa" el pensamiento. Es el tipo de escrito fragmentario que invoca una larga e ilustre tradición: Pascal, Montaigne, Novalis, Lichtenberg, Nietzsche, Benjamin, Theodor Adorno, Roland Barthes, Kostas Axelos, etc. Martín Cerda insiste en que el ensayo está compuesto de anotaciones destinadas a la composición de la obra "total". En la actualidad, los ensayos "son textos expresamente concebidos, trabajados y ejecutados como entidades formales autónomas: una forma de escritura que, en lo esencial, no sólo responde a un determinado tipo de coyunturas históricas, sino, además, a un modo de mirar, asumir y valorar el mundo a través de otras lecturas"10. La "palabrada quebrada" es la cristalización de un desgarramiento, síntoma primordial de permanecer entre las ruinas.

\footnotetext{
${ }_{9}$ Cerda, Martín (1982), La palabra quebrada, ensayo sobre el ensayo, p. 13.

${ }^{10}$ Op., cit., p. 9.
} 
El ensayo se origina a partir de una circunstancia, de una lectura o de otro escrito. Sus principales características son la ironía (estrategia de enmascaramiento) y la ocasionalidad. El ensayo está siempre ocasionado por un objeto, por una situación, por una encrucijada y orientado hacia la verdad; su palabra no pretende ser la última ni ser exacta. Por eso que el ensayo es la glosa que explica o aclara al margen de otros textos los puntos oscuros de esos escritos ajenos. En la nota pone de manifiesto que algo ocurre en el texto y a nivel de consciencia, constata, muestra, sugiere. Y en el artículo, interpreta, ensaya preguntando o enmascarando problemas e incertidumbres. Entre las diversas variedades que admite el ensayo, el más completo es el Ensayo Conceptual, el que "hace época", el que plantea los mayores problemas y las incertidumbres más radicales de una época de demoliciones, destrucciones y devastaciones; es decir, de las ruinas en el sentido de que no existe orientación para construir lo nuevo, ninguna fuerza transformadora en movimiento, ni energía capaz de reemplazar a los que perecieron"11. En el Ensayo Conceptual opera el auténtico pensador, "ese hombre cuyo destino consiste en representar simbólicamente su tiempo por medio de sus intenciones y conceptos personales. No puede elegir. Piensa como tiene que pensar, y lo verdadero para él, es, en último término, lo que con él ha nacido" ${ }^{\prime 2}$ ¿El capitalismo se instaló en la tierra bajo el presagio de la eternidad?

Finalmente, así como lo distintivo de la literatura es la literaturidad, que reconocemos en su propio y particular horizonte, el ensayo también es un género, "una técnica de variación, la moral de las formas, un acto de solidaridad histórica, porque a través de ellas es que cada escritor decide, si no para quién escribe, por lo menos cómo escribe, en un mundo cuyo curso es desconoce. La forma es un modelo de mirar, de ordenar el conflicto implícito en toda utopía"13.

\section{El Ensayista}

El ensayista es quien nace y elige el camino de registrar el vivir y el pensar en obras para los lectores de la posteridad y por la continuidad del desarrollo de las ideas como la herencia más preciosa de las nuevas generaciones.

Martín Cerda, en vida, alcanzó a recibir tres premios: el Municipal de Santiago, en 1982; el de los Juegos Literarios Gabriela Mistral en 1983 y el de la Academia Chilena de la Lengua, en 1984. Cuando recibió el reconocimiento en el seno de la Academia, agradeció diciendo:

"La Palabra quebrada es un texto biográfico; allí se asoma la vida de un hombre ocupado en leer, glosar e interpretar lo escrito por otros hombres (...) El ensayista es un lector que no se contiene frente a cada texto leído, sino que, por un impulso vital, siempre lo sobrepasa, lo interroga y lo prolonga (...) El ensayista es quien se observa leer y, encima, escribe cada una de sus observaciones (...) Leer, glosar e interpretar, son tres momentos de esta ocupación, faena en lenguaje de Ortega que Montaigne elevó a forma mayor hace cuatro siglos y que, desde entonces, llamamos ensayo"14.

\footnotetext{
${ }^{11}$ Cerda, Martín (1997), Palabras sobre palabras, p. 132.

12 Op., cit., p. 138.

${ }^{13}$ Cerda, Martín (2008), Escombros, apuntes sobre literatura y otros asuntos, p. 203.

${ }^{14}$ Cerda, Martín (1997), Palabras sobre palabras, pp. 89-90.
} 
Comentando el ensayo de Görg Lukács El Almas y las forma y la teoría de la novela (1911), se pregunta por qué el ensayista es un adelantado de manera similar a los grandes poetas; y lo es porque el buen ensayista es quien tiene la habilidad de adelantar preguntas que la mayoría aún no se ha planteado, e incluso rescata preguntas que podrían haber olvidado los filósofos y hasta las ciencias. Nada ni nadie es inocente. En la tercera parte de La palabra quebrada, ensayo sobre el ensayo (1982), se hace referencia a un siglo XX que la humanidad va abandonando antes que concluya su tiempo calendario. Naufragio de la vida privada que alcanza un nuevo escenario imperial en los ídolas de Bacon "y la servil fascinación que, sobre todo en este siglo, ejercen las figuras tutelares de la política, el deporte y el espectáculo: dictadores, campeones y estrellas"15.

Pareciera ser que el modelo de ensayista es no distanciarse de la herencia de Michel de Montaigne, a quien las editoriales y los críticos, entre los años 1960 y 1985, multiplicaron y volvieron a referirse a las ediciones de sus Ensayos. Peter Burke, en la década de los 80 del siglo pasado, consideraba a Montaigne como un contemporáneo. Martín Cerda, en una de sus notas periodísticas, considera que la ironía es el rasgo esencial, preguntas encubiertas o disimuladas que enderezan las costumbres, opiniones y sucesos de una época, anticipando la crítica a los rasgos más acusados de una determinada sociedad. El relativismo de Montaigne se desarrolló en su ensayo Apología de Raimundo Sabunde (1569), fundado en la diversidad de usos y costumbres. Para comprender que a los demás hay que asumirlos en la diversidad de creencias y saber responder a las preguntas sobre sus fundamentos, no sólo en el plano religioso, sino también en el de las ciencias.

\section{El Crítico}

Es obvio que el crítico es quien ejerce el oficio de la crítica; es quien se justifica a la saga de la invención literaria. Es testigo de la lectura del otro después de mirar su propia lectura. No puede suplantar al lector. El crítico es quien "sólo marca un texto con un cierto método de lectura, intentando construir un espacio figurado donde el pensamiento del autor puede escuchar su lenguaje (...) Es la voluntad de entender"16. La vigencia de la crítica está siempre vinculada a la historia de la lectura. Finalmente, la crítica, del mismo modo que el ensayo del que deriva, es un gesto dubitativo, un acto de desconfianza frente al valor de la tradición, un combatir sin cuartel frente a los tópicos, los prejuicios y las supersticiones ${ }^{17}$.

\section{CONCLUSIÓN}

La ensayística de Martín Cerda es un círculo hermenéutico que acumula tensiones a partir del clásico reconocimiento y protagonismo del autor, de la obra y del lector. En este círculo el autor es su pensador; la obra es el resultado de disquisiciones y preguntas que emergen hacia la realidad del mundo a través de la forma. El lector, es la posibilidad de compartir un destino desde la observación atenta de la realidad

\footnotetext{
${ }^{15}$ Cerda, Martín (1982), La palabra quebrada, ensayo sobre el ensayo, p. 73.

${ }^{16}$ Cerda, Martín (1993), Ideas sobre el ensayo, p. 196.

${ }^{17}$ Cf. La nota "Confesión crítica" que aparece en Palabras sobre palabras, pp. 73-74.
} 
que se va incubando al interior del lenguaje. El lector, en la medida que transita del margen al núcleo de su escritura en un incesante ir y venir interrogativo, propone y se propone un nivel de discusión allí donde el pensamiento aún se mantiene con vida... ¿Cuáles han sido las palabras que han gobernado el mundo?

¿Cuáles las ortodoxias que excluyen u obligan a pertenecer a grupos que separan y enemistan a unos hombres de otros, a base de argumentaciones basadas en antecedentes "objetivos"?

¿Para qué sirvieron las dictaduras del siglo XX? Quienes las abrazaron como un don salvífico ¿reflexionaron o imaginaron siquiera qué iban a salvar?

Martín Cerda advertía que las ideas trabajan siempre con el futuro. Decía que "son el aporte humilde que un hombre, usualmente apaleado por la adversidad y la incomprensión, hace a otros hombres que, desde el próximo horizonte, anuncian que todavía es posible otra vida"18.

Asumirse en la escritura es aceptar la aventura y el destino de los navegantes de antaño, que se adentraban en el mar dejando un puerto conocido y con la incerteza desplegada de no saber cuándo ni a qué puerto arribar. La aventura de saberse con la cabeza puesta en el lugar de las ideas y aceptar que la imaginación es una de las principales facultades de la inteligencia.

\section{BIBLIOGRAFÍA}

Cerda, Martín (1988), “La biografía como género", en La invención de la memoria, Jorge Narváez. Santiago, Editorial Pehuén, pp. 23-28.

Cerda, Martín (1992), La palabra quebrada, ensayo sobre el ensayo. Chile, UCV, 120 pp.

Cerda, Martín (1993), Ideas sobre el ensayo. Santiago, Dibam, recopilación de A. Calderón y P.P. Zegers. 261 pp.

Cerda, Martín (1988), "Vigencia de Montaigne", Suplemento Diario "La Época", $28 / 10 / 88$.

Cerda, Martín (1984), “Los escritores deben enseñar a convivir", Diario "La Tercera de la Hora", Revista Buen Domingo, 29/04/ 84.

Cerda, Martín (1988), “Montaigne, hoy". Diario "La Época”, Suplemento de Literatura, $\mathrm{N}^{\circ} 28,23 / 19 / 88$.

Cerda, Martín (1989), “Un libro precursor: El alma y las formas". Diario "La Época”, Suplemento de Literatura $N^{\circ} 52,23 / 04 / 89$.

\footnotetext{
${ }^{18}$ Cerda, Martín (2008), Escombros, apuntes sobre literatura y otros asuntos, p. 7.
} 
Cerda, Martín (1989), "De la revolución al romanticismo". Diario "La Época", Suplemento de Literatura $\mathrm{N}^{\circ} 65,6 / 07 / 89$.

Cerda, Martín (1987), "El arte de la novela (sobre Milan Kundera)". Conferencia dictada en el Instituto de Cultura Francesa.

Cerda, Martín (1987), "Reflexiones sobre un anarquista inteligente". Diario "La Época", entrevista, 17/09/87.

Cerda, Martín (1986), "Mala pata si la sociedad se puso macabra”, entrevista de Pablo Azócar. Revista Apsi N 178, 5/05/86.

Cerda, Martín (1985), “Luchando contra las máscaras", entrevista en Revista Hoy, No 390, 13/01/85, pp.45-46.

Cerda, Martín (1990), "Incendio dejó a Martín Cerda sin biblioteca", noticia en Diario "La Época", 15/08/90.

Cerda, Martín (1972), “El escritor no es un médium ni un iluminado”, entrevista en el Diario “El Mercurio" de Santiago, 13/11/72.

Cerda, Martín (1984), “Discurso en la Academia”, en Revista Huelén N 13, mayo-abril de 1984.

Cerda, Martín (1986). “Taller de ensayo y crítica, diez lecciones", SECH, mayo-junio de 1986 (para una teoría crítica del ensayo y tres modelos para una práctica: socio-crítica, psico-crítica y crítica histórica).

Cerda, Martín (1971), "Sobre literatura comprometida, respuesta global". Revista Taller de Letras, N 1, UC, 1971, pp. 104-108. Santiago, Chile.

Cerda, Martín (2008), Escombros, apuntes sobre literatura y otros asuntos. Santiago, Ediciones UDP., edición y prólogo de Alfonso Calderón. 317 pp.

Cerda, Martín (1997), Palabras sobre palabras. Santiago, Dibam, recopilación de Alfonso Calderón y P. Pablo Zegers.

Calderón, Alfonso (1991), “El joven Martín Cerda”, Diario “La Época”, Suplemento Literario $\mathrm{N}^{\circ} 176,25 / 08 / 91$.

De la Fuente, José (1999), "Zarpe y naufragio de Martín Cerda", en Revista Literatura y Lingüística, Chile, UCSH, No 12, pp. 183 a 196.

Lafourcade, Enrique (1984), "El estradivarius de Martín Cerda". Diario "El Mercurio" de Santiago, pp. D-32, 9/01/84. 